\title{
PREPARATION AND CHARACTERIZATION OF POLYMER BIOCOMPOSITES BASED ON LINEAR LOW DENSITY POLYETHYLENE AND RICE HUSKS
}

\author{
${ }^{1}$ Emi GOVORCIN BAJSIC, ${ }^{1}$ Nikolina MRKONJIĆ, ${ }^{1}$ Veljko FILIPAN, ${ }^{1}$ Igor SUTLOVIĆ, \\ ${ }^{2}$ Emilija ZDRAVEVA \\ ${ }^{1}$ University of Zagreb, Faculty of Chemical Engineering and Technology, Zagreb, Croatia, EU, \\ egovor@fkit.hr; nmrkonic@fkit.hr; vfilipan@fkit.hr; isutlo@fkit.hr \\ 2University of Zagreb Faculty of Textile Technology, Zagreb, Croatia, EU, \\ emilija.zdraveva@ttf.hr
}

https://doi.org/10.37904/nanocon.2019.8450

\begin{abstract}
Ecological concern has recently resulted in a natural sources which are rich in cellulose, cheap and provide good prospective as reinforcements fillers in polymer matrix composites as recyclability and environmental safety. Rice husk is a cellulose-based fibrous material and a waste product of the rice processing industry. Biocomposites made from linear low density polyethylene (LLDPE) and rice husks (RH) in different content $(10,20,30,40,50$ wt. \%) were prepared by melt compounded in laboratory Brabender mixer. The LLDPE/RH biocomposites were characterized by using differential scanning calorimetry (DSC), dynamic mechanical analysis (DMA) and thermogravimetric analysis (TGA). The effects of RH content on the thermal properties of the biocomposites have been discussed. The DSC results showed that the addition of the $\mathrm{RH}$ and increasing the RH content in biocomposites increased the crystallinity degree of the LLDPE/RH biocomposites at lower filler concentration of $\mathrm{RH}$, i.e. 10 and $20 \mathrm{wt}$ \% due to nucleating ability of $\mathrm{RH}$. The results obtained by DMA analysis show a decrease of glass transition temperature ( $\left.T_{g}\right)$ of LLDPE when it was blended with RH. In terms of thermal stability it has been found that the addition of $\mathrm{RH}$ decreased the thermal stability of the neat LLDPE.
\end{abstract}

Keywords: Linear low density polyethylene (LLDPE), rice husk (RH), biocomposites, thermal properties, thermal stability

\section{INTRODUCTION}

Usually biocomposites consist of a biodegradable polymer matrix and biofibers as reinforcement. Since both components are biodegradable, it is expected that the composite will be biodegradable as well. Biopolymers are usually biodegradable but do not possess the required thermal and mechanical properties required for engineering plastics. On the other hand, the best engineering plastics are obtained from synthetic polymers, but they are not biodegradable. The advantages of biofibers over traditional reinforcements such as glass fibers, talc and mica are low price, low density, high toughness, acceptable specific strength, good thermal properties and biodegradability [1]. The main drawback is that they are hydrophilic, thus affecting their compatibility with the hydrophobic polymer during production. Another disadvantage is the low processing temperature required by the fibers due to their possible degradation at higher temperature and volatilization of substances that may affect the properties of the composite. The processing temperature is therefore limited for most of the plant fibers up to $200^{\circ} \mathrm{C}$, although it is possible to use higher temperatures over short periods of time [2]. In the biocomposites the biofibers serve as reinforcements that increase the strength and rigidity of the composite. The reinforced polymer composites have several advantages such as: low price, biodegradability, they are renewable and have no health hazards [3]. The most commonly used types of biopolymers as food packaging materials are natural polymers such as: cellulose, starch, chitosan, and agar derived from carbohydrates, as well as: gelatin, gluten, whey protein and collagen derived from proteins. Agricultural plants are a source of raw materials for the production of natural fibers, independent of oil 
derivatives and therefore particularly interesting due to their availability, renewability and acceptability from the point of view of environmental protection. Recent research in the field of polymer materials aims at finding new types of composites, especially those with natural fibers. Rice husks are lignocellulosic materials or agricultural industrial waste obtained as the by-product of the rice processing and is particularly important natural resource. Compared to wooden biocomposites, biocomposites reinforced with rice husks exhibit excellent chemical resistance, good mechanical properties, greater dimensional stability when exposed to moisture and lower cost. Cellulose is a partially crystalline polysaccharide while hemicellulose is a highly crosslinked amorphous polymer. Cellulose has better mechanical properties than most commonly used reinforcements and offers exceptional benefits such as biodegradability and biocompatibility, high strength and low density. To achieve better adhesion of the fibers within the polymer matrix the ash content as well as the fat must be minimal. The fats reduce the interlayer adhesion and as a result, the composite is disintegrated. The hydroxyl groups present in the cellulose of natural fibers reduce the interfacial interactions thus the composite is more hydrophilic. Lignocellulose natural fibers are biodegradable because organisms recognize a hydrocarbon polymer, mainly hemicellulose in the cell wall and have specific enzymes capable of converting it into digestive units [4]. The main focus of this paper is the fabrication of biocomposites containing fine minced rice husks $(\mathrm{RH})$ in a linear low density polyetylene (LLDPE), thus to produce biodegradable polymeric material reinforced with waste or rice husks, as an alternative low cost LLDPE filler. After the preparation of the biocomposites, the influence of the rice husks contents (of 10, 20, 30, 40 and $50 \mathrm{wt} \%$ ) on the thermal properties of LLDPE/RH biocomposites was investigated.

\section{EXPERIMENTAL}

\subsection{Materials}

The biocomposites on the base of the linear low density polyethylene (LLDPE) LLDPE-EFDA 7047, with a MFR of $1.0 \mathrm{~g} / 10 \mathrm{~min}$ at $190{ }^{\circ} \mathrm{C}$ and density of $0.918 \mathrm{~g} / \mathrm{cm}^{3}$ was supplied from Equate Pertrochemical Company, Kuwait. The rice husks $(\mathrm{RH})$ were obtained from Kocani, Macedonia, and the rice cultivar was 'Sant Andrea' (Oryza sativa L. 'Sant Andrea'), Italy.

\subsection{Preparation of LDPE/RH biocomposites and films}

Biocomposites were prepared by mixing of LLDPE and RH in the Brabender mixer at the temperature of $170{ }^{\circ} \mathrm{C}$ for $5 \mathrm{~min}$. The content of $\mathrm{RH}$ was $10,20,30,40$ and $50 \mathrm{wt}$. \%. Before mixing with LLDPE the RH were dried for $24 \mathrm{~h}$ at $105^{\circ} \mathrm{C}$ to remove any residual water. The LLDPE/RH films were pressed in a hydraulic press Fontune, Holland (SRB 140, EC $320 \times 320 \mathrm{NB}$ ) at the temperature of $160^{\circ} \mathrm{C}$ and a pressure of $25 \mathrm{kPa}$ for $5 \mathrm{~min}$.

\subsection{Characterization}

Thermal transitions and related heat fusion of the neat LLDPE and LLDPE/RH biocomposites were studied using a differential scanning calorimeter DSC Mettler Toledo 822e. Dynamic measurements were performed in the temperature range from -100 to $150{ }^{\circ} \mathrm{C}$ with rate of $10{ }^{\circ} \mathrm{C} / \mathrm{min}$, in two heating/cooling cycles and inert atmosphere of nitrogen.

Dynamic mechanical measurements are performed with a TA Instruments model DMA 983 Analyzer. The measurements are conducted over temperature range of $-100{ }^{\circ} \mathrm{C}$ to $150^{\circ} \mathrm{C}$ at a constant frequency of $1 \mathrm{~Hz}$ with amplitude of $0.3 \mathrm{~mm}$. The heating rate was $3^{\circ} \mathrm{C} / \mathrm{min}$. The samples were cooled to $-100{ }^{\circ} \mathrm{C}$ using liquid nitrogen.

In order to obtained the thermal stability thermogravimetric analysis was performed under a nitrogen atmosphere $(60 \mathrm{ml} / \mathrm{min})$ on a TA Instruments Q500 system analyzer. Samples of approximately $10 \mathrm{mg}$ was heated from $25^{\circ} \mathrm{C}$ to $600^{\circ} \mathrm{C}$ ar a eating rate of $10^{\circ} \mathrm{C} / \mathrm{min}$. 


\section{RESULTS AND DISCUSSION}

\subsection{Thermal behaviour of LLDPE/RH biocomposites}

The thermal behavior of LLDPE/RH biocomposites was investigated by means of DSC measurement. The DSC curves during heating and cooling of the neat LLDPE and LLDPE/RH biocomposites are shown in Figures $1 \mathrm{a}$ and $1 \mathrm{~b}$ respectively.
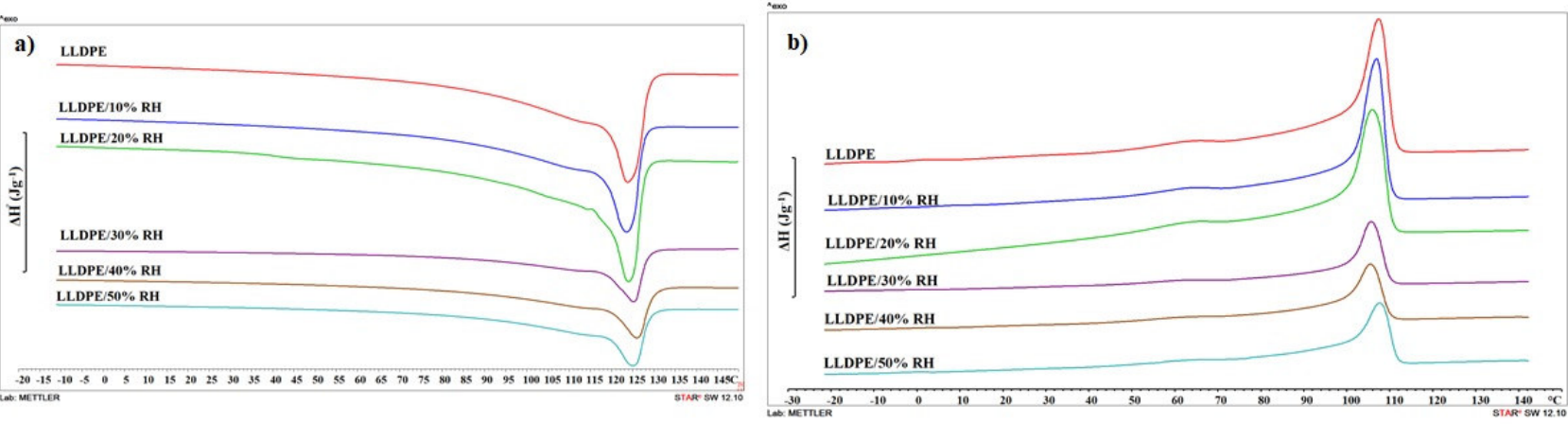

Figure 1 DSC curves of the neat LLDPE and LLDPE/RH biocomposites during heating (a) and cooling (b)

The DSC heating curve of the neat LLDPE (Figure 1 a) shows melting temperature $\left(\mathrm{T}_{\mathrm{m}}\right)$ at $123.1^{\circ} \mathrm{C}$ and crystallization temperature at $108.0^{\circ} \mathrm{C}$. Table 1 gives the peak melting and crystallization temperatures and the heat of melting $(\Delta \mathrm{H})$. From DSC curves and the $T_{m}$ values in Table 1 it can be seen very small $\left(2{ }^{\circ} \mathrm{C}\right)$ change in the $T_{\mathrm{m}}$ of the LLDPE crystalline phase by incorporation of $\mathrm{RH}$ and with the increase of their content. The added $\mathrm{RH}$ had no significant effect on the polymer melting point. The addition of the $\mathrm{RH}$ has decreased the crystallization temperature, $T_{c}$. This decrease in $T c$ suggested on the slower crystallization of LLDPE with the addition of $\mathrm{RH}$. Degree of crystallinity, $\chi_{\mathrm{c}}$, for LLDPE and LLDPE/RH biocomposite was determined according to Equation (1) and it increases at lower content of $\mathrm{RH}$ (10 and $20 \mathrm{wt} \%$ ) (Table 1), what means that $\mathrm{RH}$ act as nucleating agens for LLDPE. In regard to the $\chi_{\mathrm{c}}$ it is seen that the increase of the RH content (30, $40,50 \mathrm{wt} \%$ ) reduces the $\chi_{c}$, which suggests that the highest reduction in the crystalline phase of the LLDPE obtained.

$\chi=\left(\frac{\Delta \mathrm{Hm}}{\Delta \mathrm{H}^{0} \mathrm{~m} \times\left(1-\frac{\% \mathrm{RH}}{100}\right)}\right) \times 100$

where:

$\Delta \mathrm{H}_{\mathrm{m}}$ - the value of melting enthalpy read from the surface of melting endothermn $\left(\mathrm{Jg}^{-1}\right)$

$\Delta \mathrm{H}_{\mathrm{m}}{ }^{\circ}$ - the melting enthalpy of $100 \%$ crystalline LLDPE $\left(293,0 \mathrm{Jg}^{-1}\right)$.

Table 1 DSC results after $2^{\text {nd }}$ heating/cooling cycle of the neat LLDPE and LLDPE/RH biocomposites

\begin{tabular}{|c|c|c|c|c|}
\hline Sample & $\begin{array}{c}\mathbf{T}_{\mathbf{m}} \\
\left({ }^{\circ} \mathbf{C}\right)\end{array}$ & $\begin{array}{c}\mathbf{T}_{\mathbf{c}} \\
\left({ }^{\circ} \mathbf{C}\right)\end{array}$ & $\begin{array}{c}\Delta \mathbf{H}_{\mathbf{m}} \\
\left(\mathbf{J g}^{-1}\right)\end{array}$ & $\begin{array}{c}\chi_{\mathbf{c}} \\
(\%)\end{array}$ \\
\hline LLDPE & 123.1 & 108.0 & 118.18 & 40.33 \\
\hline LLDPE $/ 10 \% \mathrm{RH}$ & 123.0 & 107.7 & 115.37 & 43.75 \\
\hline LLDPE /20\% RH & 123.4 & 106.7 & 120.12 & 51.25 \\
\hline LLDPE /30 \% RH & 125.0 & 106.0 & 50.41 & 24.58 \\
\hline LLDPE /40\% RH & 125.8 & 105.8 & 55.34 & 31.48 \\
\hline LLDPE $+50 \% \mathrm{RH}$ & 124.7 & 108.0 & 58.11 & 39.67 \\
\hline
\end{tabular}




\subsection{Results of Thermogravimetric Analysis (TGA)}

A TG analysis was very useful tehnique to determine quantitatively the degradation behavior, the composition of the materials and thermal stability. In this study the thermal stability of the neat LLDPE and LLDPE/RH biocomposites was investigated. The decomposition temperature for each step and the residue of the neat LLDPE and LLDPE/RH biocomposites under nitrogen atmosphere are observed from Figure 2.
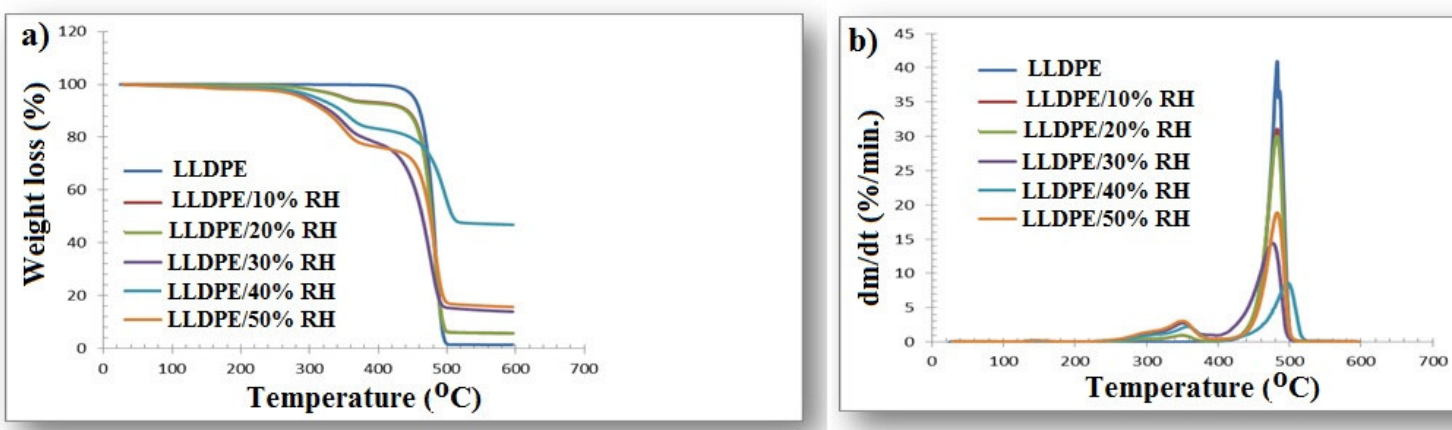

Figure 2 TG curves a) and DTG curves b) of the neat LLDPE and LLDPE/RH biocomposites

The TGA results are presented in Table 2 which including the initial degradation temperature $\left(T_{\text {ini. }}\right)$, the temperature corresponding to final temperature of thermal degradation $\left(T_{\text {end }}\right)$ temperature at the maximum rate of degradation ( $\mathrm{T}_{\max }$ ) and the residual mass of the composites at $600^{\circ} \mathrm{C}$. From the Figure 2a can be seen that the TG curve displays a main degradation step and almost no residue $(1.41 \%)$ is left for the neat LLDPE. The DTG curve (Figure 2b) shows a single peak with an inflection point at $482.9^{\circ} \mathrm{C}$ where LLDPE degraded at the maximum rate. DTG curves showed the three stage degradation behavior for the LLDPE/RH biocomposites. The first stage, between 100 and $200{ }^{\circ} \mathrm{C}$ represented the loss of water that inside $\mathrm{RH}$, the second stage corresponds to the degradation of $\mathrm{RH}$ while the third stage of degradation corresponds to the degradation of LDPE. The final decomposition temperature of the LLDPE/RH biocomposites in the present research work is closer to $\mathrm{T}_{\text {fin }}$ of LLDPE. From Table 2, it is clear that the addition of RH decreased the thermal stability of the biocomposites, also the thermal stability decreased with increasing $\mathrm{RH}$ content. This is due to the lower thermal stability of the $\mathrm{RH}$. The residue at $600{ }^{\circ} \mathrm{C}$ increased with increasing $\mathrm{RH}$ content (Table 2).

Table 2 TGA results of the neat LLDPE and LLDPE/RH biocomposites

\begin{tabular}{|c|c|c|c|c|c|}
\hline Sample & $\mathbf{T}_{\text {ini. }}\left({ }^{\circ} \mathbf{C}\right)$ & $\mathbf{T}_{\text {fin. }}\left({ }^{\circ} \mathbf{C}\right)$ & $\mathbf{T}_{\max }{ }^{1}\left({ }^{\circ} \mathbf{C}\right)$ & $\mathbf{T}_{\mathbf{m a x}^{2}}\left({ }^{\circ} \mathbf{C}\right)$ & $\begin{array}{c}\text { Residue at } \mathbf{6 0 0} \\
(\mathbf{\%})\end{array}$ \\
\hline LLDPE & 451.5 & 494.5 & $/$ & 482.9 & 1.41 \\
\hline LLDPE/10 \% RH & 350.4 & 495.6 & 349.3 & 482.8 & 5.77 \\
\hline LLDPE/20 \% RH & 347.3 & 494.4 & 350.9 & 482.3 & 5.68 \\
\hline LLDPE/30 \% RH & 293.9 & 490.3 & 351.6 & 475.9 & 13.96 \\
\hline LLDPE/40 \% RH & 309.0 & 510.3 & 357.0 & 497.3 & 46.88 \\
\hline LLDPE/50 \% RH & 288.2 & 494.0 & 349.9 & 482.6 & 15.76 \\
\hline
\end{tabular}

\subsection{Dynamic Mechanical Analysis (DMA) results}

DMA allows measurement of the storage modulus ( $\left.E^{\prime}\right)$ characteristic of the stiffness, and loss modulus ( $\left.E "\right)$ characteristic of damping at different temperatures. Figure 3 shows the storage modulus ( $\left.E^{\prime}\right)$ and loss modulus( $E ")$ of the neat LLDPE and RH reinforced LLDPE biocomposites as a function of temperature. 

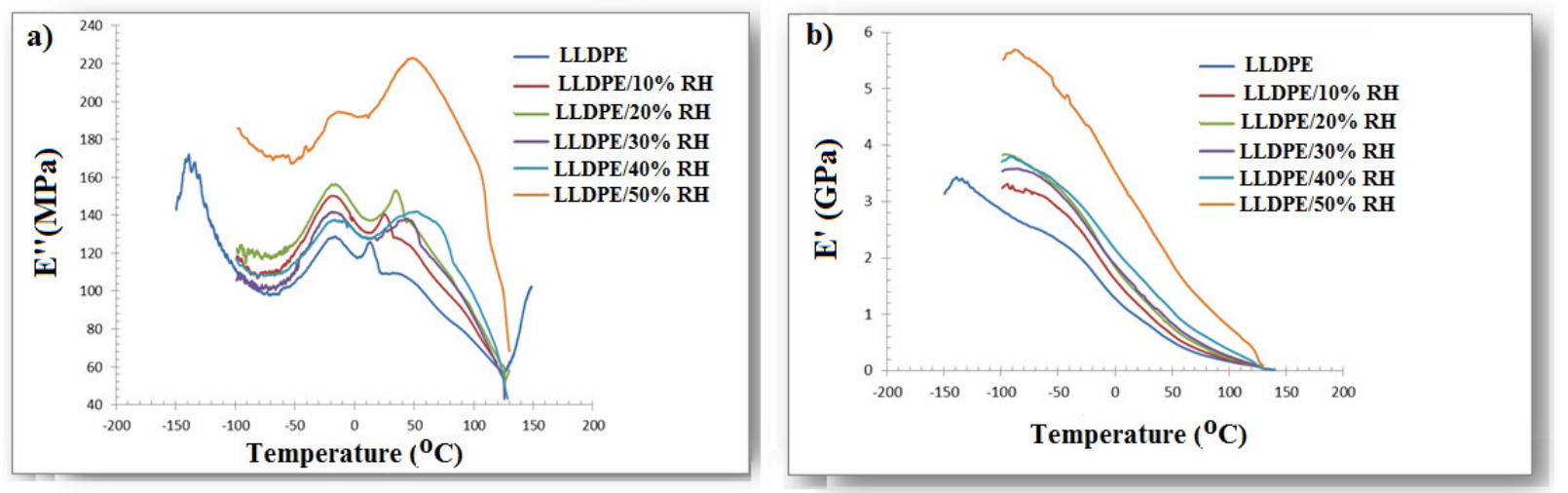

Figure 3 DMA curves of Loss modulus a) and Storage modulus b) of the neat LLDPE and LLDPE biocomposites

The E"curves of the neat LLDPE and LLDPE/RH biocomposites with different RH content as a function of temperature is shown in Figure 3a. All curves exhibit two relaxation peaks in the range of temperature analyzed. The low relaxation peak is related to the glass-rubber transition of the amorphous phase of LLDPE and is taken as the glass transition temperature $\left(T_{g}\right)[5,6]$. It can be seen that the area under these peaks decreases with $\mathrm{RH}$ content and this is easily related to the decreasing LLDPE concentration in the biocomposites. The high temperature peak corresponds to the $\alpha_{\mathrm{h}}$ transition related to the LLDPE crystalline fractions $[5,6]$. The glass transition temperature, $T_{g}$, obtained from $E$ " and temperature $\alpha_{h}$ transition are shown in Table 3. The LLDPE $T_{g}$ determined from the E" curves showed a marginal decreasing in the presence of $\mathrm{RH}$, from -16 to $-17^{\circ} \mathrm{C}$. As the $\mathrm{RH}$ content increased the mobility of LLDPE chains increased. Figure $3 \mathbf{b}$ shows the temperature dependence of the storage modulus ( $\left.E^{\prime}\right)$ for the neat LLDPE and LLDPE/RH biocomposites with different $\mathrm{RH}$ content. It was observed that $E^{\prime}$ of all the biocomposites increased with higher $\mathrm{RH}$ content across the entire temperature range due to the enhanced stiffness, as can be seen from Figure $\mathbf{3 b}$ and Table 3. Increasing the RH content a significant improvement of stiffness was verified. This is the expected effect caused by the addition of more rigid fillers into semi-rigid polymer matrices.

Table 3 TGA results of the neat LLDPE and LLDPE/RH biocomposites

\begin{tabular}{|c|c|c|c|}
\hline Sample & $\begin{array}{c}\mathbf{T}_{\mathbf{g}} \\
\left({ }^{\circ} \mathbf{C}\right)\end{array}$ & $\begin{array}{c}\alpha_{\mathbf{h}} \\
\left({ }^{\circ} \mathbf{C}\right)\end{array}$ & $\begin{array}{c}\mathbf{E}^{\prime}{ }^{\circ}{ }^{\circ} \mathbf{C} \\
(\mathbf{G P a})\end{array}$ \\
\hline LLDPE & -16.6 & 12.6 & 0.8730 \\
\hline LLDPE $/ 10 \% \mathrm{RH}$ & -17.2 & 25.4 & 1.086 \\
\hline LLDPE $/ 20 \% \mathrm{RH}$ & -17.2 & 35.2 & 1.265 \\
\hline LLDPE $/ 30 \% \mathrm{RH}$ & -18.0 & 44.4 & 1.327 \\
\hline LLDPE $/ 40 \% \mathrm{RH}$ & -17.2 & 50.2 & 1.600 \\
\hline LLDPE $/ 50 \% \mathrm{RH}$ & -14.6 & 48.2 & 2.727 \\
\hline
\end{tabular}

\section{CONCLUSION}

The DSC results showed that the addition of the $\mathrm{RH}$ and increasing the $\mathrm{RH}$ content in the LLDPE/RH biocomposites increased the crystallinity degree of the biocomposites at lower filler concentration of $\mathrm{RH}$ (10 and $20 \mathrm{wt} . \%$ ) due to nucleating ability of $\mathrm{RH}$. But the crystallinity degree was reduced on addition 30,40 and $50 \mathrm{wt} \%$ of $\mathrm{RH}$. This may be attributed to the presence of the higher concentration of the silica from the $\mathrm{RH}$ in the crystal structure of LLDPE. The melting temperature of the biocomposites was not significantly changed, 
the $T_{\mathrm{m}}$ was slightly increased with increasing $\mathrm{RH}$ content $(30,40$ and $50 \mathrm{wt} \%$ of $\mathrm{RH})$. In terms of thermal stability it has been found that the addition of $\mathrm{RH}$ decreased the thermal stability of the neat LLDPE. Initial degradation temperature of LLDPE/RH biocomposites decreased with the increasing of $\mathrm{RH}$ content suggesting that the biocomposites are less thermally stable. The results obtained by DMA analysis show a decrease of glass transition temperature $\left(T_{g}\right)$ of LLDPE when it was blended with $\mathrm{RH}$, mobility of LLDPE chains increased.

\section{REFERENCES}

[1] TANG, X.Z.; KUMAR, P.; ALAVI, S.; SANDEEP, K.P. Recent Advances in Biopolymers and Biopolymer-Based Nanocomposites for Food Packaging Materials Critical Reviews in Food Science and Nutrition. 2012, vol.52, no. 5 , pp. 426-442.

[2] WANG, W., SAIN, M. and COOPER, P. A. Hygrothermal weathering of rice hull/HDPE composites under extreme, climatic conditions. Polymer Degradation and Stability, 2005, vol. 90, no.3, pp. 540-545.

[3] THWE, M. M. and LIAO, K. Effects of environmental aging on the mechanical properties of bamboo-glass fiber reinforced polymer matrix hybrid composites. Composite. Part A Applied Science and Manufacturing, 2002, vol. 33, no. 1, pp. 43-52.

[4] ROWELL, R. M., in: Emerging Technologies for Materials and Chemicals, ROWELL, R. M., SCHULTZ, T. P., NARAYAN, R., Eds., 1992, 12, 476,

[5] YEONG-TARNG, S. and HUI-CHUN, C. DSC and DMA studies on silane-grafted and water-crosslinked LDPE/LLDPE blends. Journal of Applied Polymer Science, 2001, vol.81, no.7, pp.1808-1816.

[6] KONTOU, E. A. and NIAOUNAKIS, M, Thermo-mechanical properties of LLDPE/SiO 2 nanocomposites, Polymer, 2006, vol.47, no. 4, 1267-1280. 